\title{
Maternal Mortality in Tajikistan: Successes and Challenges
}

\section{Dilofarid Miskinzod*}

\author{
Women's and Gender Studies Program, College of Social and Behavioral Sciences, Northern Arizona University, USA
}

\begin{abstract}
*Corresponding author: Dilofarid Miskinzod, Women's and Gender Studies Program, College of Social and Behavioral Sciences, Northern Arizona University, 19 W Cornell Drive Flagstaff, Arizona 86001, USA, Tel: +1-928-523-7555, Fax: 928-523-5560
\end{abstract}

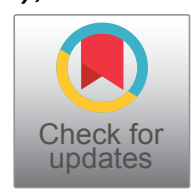

\begin{abstract}
Purpose: This study sought to explore health care providers' perceptions of the situation of maternal mortality and health.

Methods: This qualitative study was conducted with 16 health care providers working in different layers of maternal health care system in two purposefully selected research settings, Khorog town and Dushanbe, which have different social, economic and ethnic backgrounds in 2018. Semi-structured face-to-face interviews were conducted to gather the data. Duration of interviews ranged from 30-60 min. NVivo software for qualitative research was used to analyze the results.

Results: This study has clearly shown that while health care providers highlighted successful interventions such as improvement of emergency obstetric care, national standards and strengthening of referral system implemented by the government and/or international health organizations that brought down maternal mortality, they also stated that factors, including chronic diseases and geographic disparities still contribute to maternal mortality in Tajikistan. They also emphasized the obstetric transition and a need to focus on indirect causes of maternal mortality in the future.
\end{abstract}

Conclusion: The study recommends to review maternal health care policies and programs to include the most marginalized groups of women and to make maternal health care system equitable for all women in the country.

\section{Keywords}

Maternal health care system, Progress, Inequities, Challenges

\section{Introduction}

Motherhood is a crucial, positive and fulfilling experience in a life of a woman [1]. Yet in some cases, it might have adverse health outcomes, including maternal morbidity and mortality. For each female who dies in childbirth, many others develop different health issues and disability due to complications [2]. An obstetric death is a devastating event that unexpectedly ends a life of a woman and put members of her family in grief and misery [1]. It has wide-ranging adverse effects on the child, family and the larger society [3-5]. For example, the survival of infant and children under five years of age is strongly associated with nutrition of a child and other crucial care practices requiring maternal involvement [6].

Maternal mortality is a vital indicator of health care quality at the national and international level $[3,4]$. It is also an important indicator of the operation of health care systems, which shows access to and quality of maternal health care as well as the women's status of health during reproductive age [7]. Maternal mortality illustrates "the ultimate failure of perinatal medical care" (p. 105) [3]. Moreover, it is globally used as a marker of the general health of populations and development situations of a country [6-8]. Among all indicators of human development, maternal mortality demonstrates the most significant disparities between the nations in the global North and South as well as between the wealthy and the deprived ones within nations [6-9]. Ninety-nine percent $(99 \%)$ of all maternal deaths occur in the countries of the global South and only $1 \%$ of them happen in countries of the global North [10]. Ronsmans and Graham (2006) argue that maternal death "is a $21^{\text {st }}$ century problem essentially only for the poor, and one virtually eliminated for people with the means and status to access health care" (p.1189) [11].

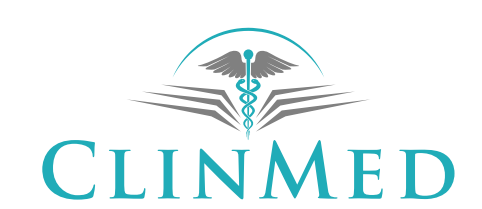

INTERNATIONAL LIBRARY

Citation: Miskinzod D (2020) Maternal Mortality in Tajikistan: Successes and Challenges. Int J Womens Health Wellness 6:111. doi.org/10.23937/2474-1353/1510111

Accepted: March 04, 2020: Published: March 06, 2020

Copyright: (c) 2020 Miskinzod D. This is an open-access article distributed under the terms of the Creative Commons Attribution License, which permits unrestricted use, distribution, and reproduction in any medium, provided the original author and source are credited. 


\section{Maternal Mortality in Tajikistan}

The data for Tajikistan before 1991 in not available because it was part of the Union of Soviet Socialist Republics (USSR) and there is only data on maternal mortality ratio (MMR) for the entire country but not for separate republics that were parts of the Soviet Union. The MMR for USSR was 43 per 100,000 live-births in 1988 and this number was four times higher than that in the Federal Republic of Germany, six times that in the UK and USA, and 15-20 times in Scandinavian countries and Canada [12].

Table 1: Characteristics of health care providers.

\begin{tabular}{|l|l|}
\hline Health care Providers details & $\mathbf{N}=16 \mathbf{( \% )}$ \\
\hline Education & \\
\hline Higher education & $16(100 \%)$ \\
\hline Place of work & $13(82 \%)$ \\
\hline Maternity hospital & $2(12 \%)$ \\
\hline Reproductive health center & $1(6 \%)$ \\
\hline Private clinic & \\
\hline Work experience, years & 0 \\
\hline $0-10$ & $1(6 \%)$ \\
\hline $10-20$ & $6(38 \%)$ \\
\hline $20-30$ & $7(44 \%)$ \\
\hline $30-40$ & $2(12 \%)$ \\
\hline $40-50$ & \\
\hline Age, years & 0 \\
\hline $20-40$ & $14(88 \%)$ \\
\hline $41-60$ & $2(12 \%)$ \\
\hline $61-80$ & \\
\hline
\end{tabular}

The Republican Medical Statistical Center (RMSC) under the Ministry of Health and Social Protection (MHSP) has only data from 2008 onwards, therefore, this paper used World Health Organization (WHO) data for Tajikistan to show changes of MMR from 1991 until 2007. In 1990, the official MMR was at 68 deaths per 100,000 live births. It then sharply increased to 120 in 1995 and then significantly decreased to 85 in 2000 and further to 59 in 2005 and approached 44 deaths per 100,000 live births in 2013 Table 1 [13]. The data show that MMR worsened dramatically following the collapse of the USSR and the civil war and then stabilized by 2005 when the government with donor support implemented several interventions in the health care sector Figure 1.

According to the RMSC, Tajikistan's MMR was 24.1 per 100,000 live-births in 2017 [14]. It continues to decrease after a sharp increase during two consecutive years (2014 and 2015) [14]. Figure 2. However, comparison between RMSC and WHO data show the discrepancies between the two statistics. These discrepancies raise concerns about quality of maternal mortality data in Tajikistan. Different scholars expressed concerns about quality of official statistics by arguing that data on maternal mortality in Tajikistan does not reflect the real situation $[15,16]$. Numbers from vital registration are incomplete and show considerably lower numbers because of underreporting [16]. The official figures do not show the real magnitude of maternal mortality because they do not cover adequately the true situation and they are not reliable [17].

Gashimov (2010) also questions "reliability and relevance" of health and demographic statistics and considers it as a serious concern and argues that the official

120

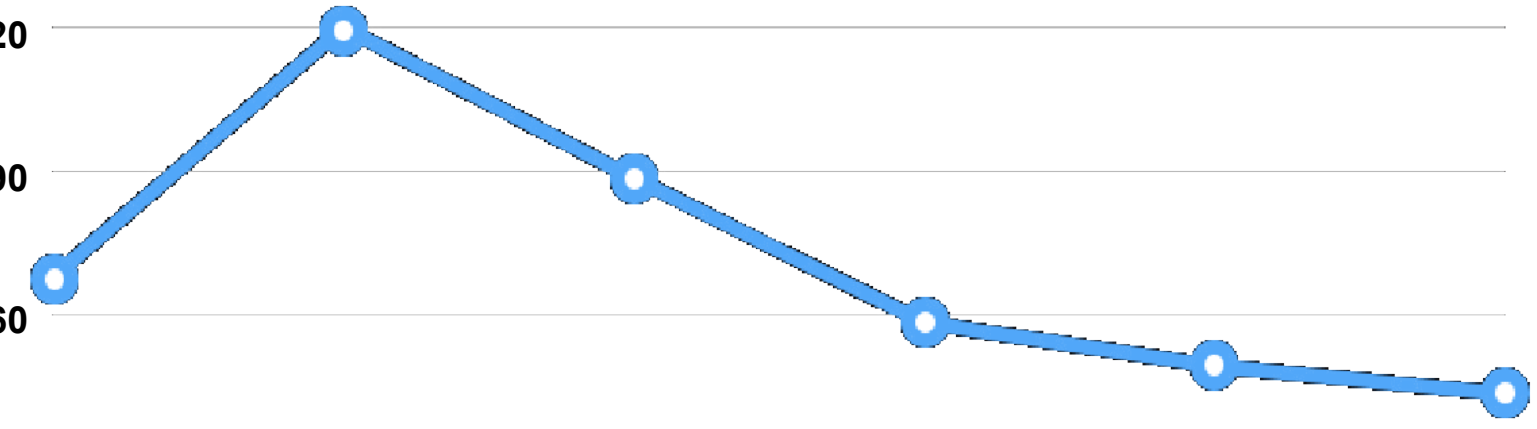

30

0 1990 1995
2000
2005

2010
2013

Source: WHO

Figure 1: Trends in maternal mortality ratio from 1990 to 2013 in Tajikistan. 


\section{Maternal Mortality Ration in the Republic of}

\section{Tajikistan}

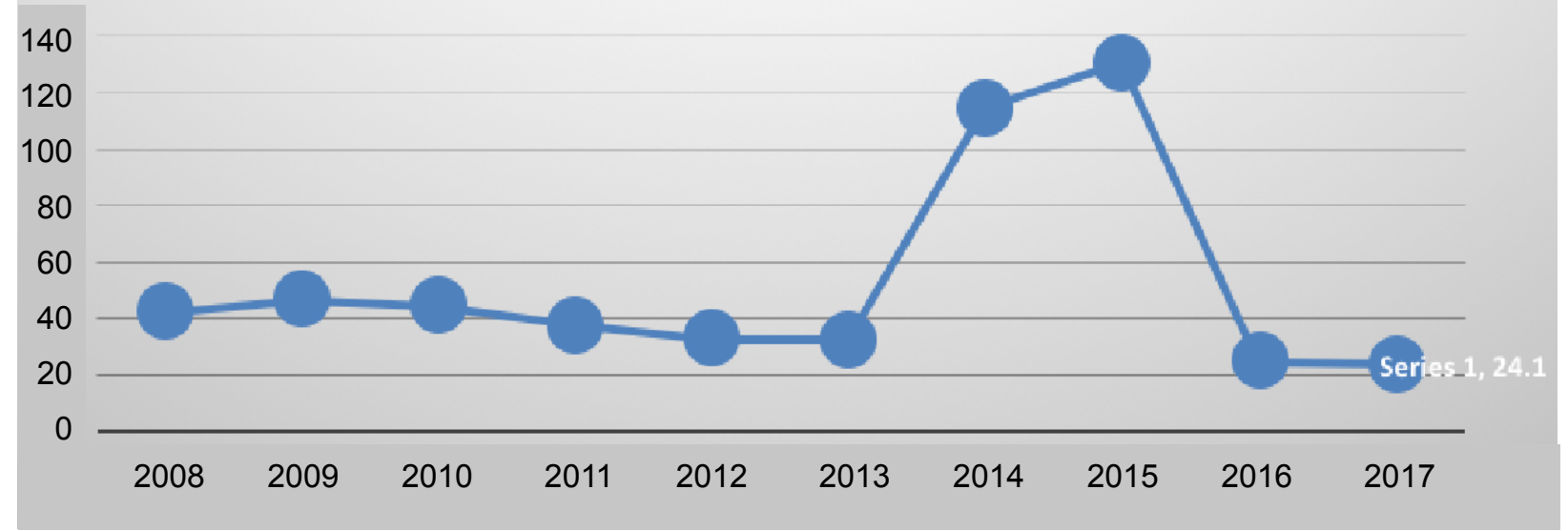

Source: RMSC.

Figure 2: Trends in maternal mortality ratio from 1990 to 2013 in Tajikistan.

indicators are not reliable because of out-of-date definitions, collection methods, underreporting and lack of full registration of important statistics. Although these sources do not explain the discrepancies between WHO and RMSC data on MMR, they help to understand that there is a long history of reliability and other issues with official statistics and there is an urgent need to improve and fix them. This study examines health providers' perceptions on the situation of maternal mortality and health and how various factors impact their service provision using a qualitative research method. The main research questions guiding the research are: How do health care providers perceive maternal health and maternal mortality in Tajikistan? How do structural, social, economic, political, health system elements and individual characteristics/identities impact maternal health and mortality? The health care providers in this study argue that improvement of emergency obstetric care, development and implementation of national standards and enhancement of referral system improved maternal health care and decreased maternal mortality in Tajikistan. The health care providers also state that there is alarming disparities in maternal mortality between urban and rural women and define chronic health diseases as a key contributing factor to maternal mortality. The study also underpins the obstetric transition and a need to focus on indirect causes of obstetric deaths in the future. The paper concludes with recommendations how to further decrease maternal mortality and improve maternal health.

\section{Material and Methods}

\section{Sample selection}

To understand the situation on maternal mortality and health and factors/causes impacting them in Tajikistan, I used a qualitative research method with so- cial constructivist and critical interpretive approaches. Respondents were eligible if they had work experience with women during pregnancy, delivery and postpartum period. They represented various layers of maternal health care system, including maternity hospitals, reproductive health centers and a private clinic Table 1.

All participants were physicians and were relatively homogeneous in terms of their education. The mean work experience of respondents who completed the interviews was 31 years Table 1.

Sixteen health providers were purposefully selected for the study. The study was conducted in two purposefully selected research settings, Khorog town and Dushanbe city, which have different social, economic and ethnic backgrounds.

\section{Data collection}

Data were collected through in-depth, semi-structured, problem-centered individual interviews with health providers. The study employed an interview guide based on prior literature and included questions about the situation regarding maternal health and mortality, where and how women delivered, the causes of maternal deaths, and strategies implemented to prevent maternal deaths in Tajikistan. The interview was translated into Shugni, Tajik, and Russian along with the consent form. The Institutional Review Board of the Northern Arizona University and the Ethical Committee of the MHSP of RT approved the study. All interviews were conducted in Shugni, Tajik, or Russian, depending on respondent's preferences. The author conducted all interviews and speaks fluently all languages. Before conducting interviews, the consent form with details of the study was provided to participants. Oral consent was obtained and 
recorded on digital recorders with the respondents' permission. The interviews were conducted face-toface in the respondents' office (private room) and lasted from 30 to 60 minutes. Three informants refused to be recorded and detailed notes were taken during these interviews. All interviews and notes were fully transcribed verbatim in the language it was originally collected in, and then translated into English for coding and analysis by the author [1].

\section{Data analysis}

The transcripts were analyzed using NVivo software for qualitative data analysis, Version 12 Plus, 2019 [18]. Transcripts were read several times before coding them for initial codes. Codes were extracted across all transcripts $^{a}$. The research questions directed initial coding and when new concepts emerged, they also guided the coding process. Single codes or those irrelevant to the research questions were removed. The remaining codes were tested against the data to guarantee reliability of coding and face validity (i.e., that they mirror the meaning of respondents). All initial codes were examined to identify overarching themes. The emerging themes were carefully and deliberately examined. Similar factors in both research settings were used to merge them into common and atypical themes. Relevant documents were also reviewed. Careful reading of documents led to creating a coding template with themes and subthemes of interest in NVivo. The coding template guided extraction of excerpts from analyzed documents and they were added to the appropriate sections of the template.

There are limitations which should be taken into consideration when considering the study findings. They include the retrospective nature of the study. The reflective nature of the interview methodology itself invites the interviewees to recall information from the past; there is, therefore, a high chance of a recall bias. The power dynamic between the interviewer and interviewee could be another limitation. Although the researcher tried to use the self-reflexivity method to avoid reproduction of inequality in the research [19].

\section{Results}

\section{Improvement of emergency obstetric care}

Qualitative findings in the research setting suggest that improvement of emergency obstetric care in maternity health facilities was defined as a main cause for a decline of maternal mortality according to health care providers ( $n=9$ ). In particular, construction of a new maternity hospital with an intensive care unit (ICU) and a laboratory, which replaced the old maternity department that did not have these structures, was un-

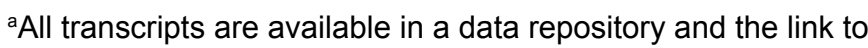
the data repository is provided. derpinned as a key factor behind decrease of maternal mortality in Khorog $(n=9)$.

Due to absence of ICU and a laboratory, the old maternity department was woefully unprepared for a maternal emergency. The health care providers suggest that ICU and a laboratory allow providing emergency life-saving obstetric care immediately without any needless delays and help save women's lives now. According to $\mathrm{R}^{\mathrm{b}}{ }^{\mathrm{b}}$ [1]: Of course, it is decreasing. We had a woman who had an eclampsia and then she developed disseminated intravascular coagulation (DIC) and when they brought her to us, we were able to save her.

Now we have an ICU inside of the hospital, we can take her to the operation room for a surgery in seconds. We do not need to wait until she develops shock, but we are able to take her to the surgery to save her. We had many patients with emergency obstetric conditions, including placenta abruption, Couvelaire uterus, we were able immediately take a woman with DIC to the surgery. We have a diagnostic laboratory right inside of the hospital. It works 24 hours a day. Before when we had women with such severe complications, we called the ICU and anesthesiologists were in surgeries in other departments (i.e. of the regional general hospital). By the time they completed their surgeries (i.e. in other departments) and were able to come to the maternity hospital, we lost our women.

This maternity hospital struggled with high MMR before. In the past health providers worked in the maternity department that along with other departments, including surgery, neurology, oncology and others, was a part of the Regional General Hospital (RGH). All these departments shared a common ICU and its doctors-anesthesiologists and rheumatologist provided emergency health services to all these departments. The respondents argue that a separate and independent ICU that now provides emergency care only to patients of the newly constructed maternity hospital was crucial for improving maternal mortality situation in this remote, poor, mountainous and hard-to-reach region of the country.

R8 states: It is decreasing, if we look at our clinic, not to put bad eyes, we did not have any maternal death in our clinic. I think it is due to the construction of a new maternity hospital. We had many cases when until anesthesiologists from the ICU got free/were able to come, and we went to the surgery or the operation room, we lost women. But we were able to save women with very severe conditions recently thanks to these improved conditions. It was impossible to do before, maybe a woman would die, this is the first reason. Improvement of working condition helped us significantly.

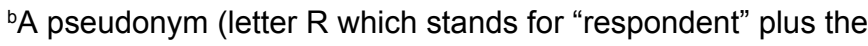
number allocated for a particular interviewee) used to provide confidentiality for the respondents of this study. 
R6 also said that: A woman can die from hemorrhage in 20 minutes. Before we had to look for a rheumatologist and then look for an operation nurse and then we will look for an anesthetist... Or another issue was a laboratory. We did not have a laboratory, they were so slow, and we needed to wait for 2-3 hours in some cases. Now that we have both of these two services, we are able to act much faster /to start performing surgeries.

\section{Importance of on-Time Referral}

Another factor that contributed to reduction of maternal mortality according to health providers $(n=8)$ is improvement of a referral system. R2 states that "it is not just quality of obstetric services and availability of emergency obstetric care after construction of the new maternity hospital improved, but also the referral of pregnant women has been improved." Health providers at the district/rural, regional and national/republican levels across the country refer pregnant women to the next level of obstetric health facilities on time so a pregnant woman with chronic health diseases and higher risk of developing complications can receive appropriate and adequate care. There is also a better coordination and collaboration among different players in maternal health system now according to providers. Improvement of referral system helped to improve organization, management and coordination of maternal health care especially for pregnant women with high-risk of developing serious obstetric complications.

R3 stated that: Because of high maternal mortality in the past, the Agha Khan Health Services (AKHS) and we (e.g. doctors of obstetricians and gynecologists) organized many seminars in the districts/rural areas on many occasions. And now when midwives notice a little divergence in the condition (i.e. women's health condition), they refer immediately them here (e.g. maternity hospital). We work together and both our and their results are good... And when pregnant women have even minor complications, midwives refer these women to us.

The referral system improved not only between midwives/nurses working in small health facilities in rural areas and doctors working in the maternity hospital in the town/region; but also between physicians working in the maternity hospital in the town/region and those working in the capital city - Dushanbe. Health professionals refer women with complications to the next level of care where more complex and comprehensive obstetric services and procedures are available. They usually refer them to one of the most eminent and accomplished obstetric health institutions in the country the National Institute of Obstetrics, Gynecology and Perinatology (NIOGP) in the capital city-Dushanbe. R8 stated: Now even in rural areas, when pregnant women have complications, their conditions are identified and they are referred on time to us. Now we also when identify pregnant women who have complications depend- ing on their condition, we might refer them on time to Dushanbe. For example, if she has an issue with neurosurgeon, we refer her on time. One of the reasons that a medical referral on site (rural areas) has improved is due to AKHS work with them (i.e. local rural health providers). The health providers are more guarded/prepared/educated in rural areas now.

R9 also said: We had women in very severe conditions and it seemed that it was impossible to save them but we did save them. However, there are many health situations when we are unable to deal with/manage them. For example, cardiovascular diseases, extra-genital diseases, thrombocytopenic purpura, we are still not able to manage and we refer women with such conditions to the NIOGP, the $1^{\text {st }}$ maternity hospital. We refer them during pregnancy; also we refer women with diabetes there.

It seems that the referral system improved also at the national/republican level. R11 working in the NIOGP stated that their collaboration with different specialists from narrow disciplines such as neurologists, cardiologists, immunologists and other experts improved in Dushanbe. The NIOGP provides a mini-bus that brings those health specialists at $2 \mathrm{pm}$ every day to the NIOGP or whenever there is an obstetric emergency case to check patients who need their consultation on various health conditions.

According to R11: Our hospital has a contract with various health professionals around the city to come and consult our patients on a regular basis. The hospital also organizes the transportation to bring them here. They usually come and provide their consultation to our patients. During emergency cases we do ask them to come as soon as possible and we provide the transportation.

\section{National Standards}

According to health providers $(n=7)$, implementation and utilization of the national standards were extremely effective in reduction of the maternal mortality. The interviews with health providers at different layers of the maternal health care system showed that the national standards are widely utilized by maternity health facilities throughout the country. They are very well embraced in public and private clinics. The providers $(n=7)$ also suggested that maternal deaths and injuries were reduced significantly after implementation of national standards. Many maternity hospitals that applied obstetric practices detailed in the national standards, were able to reduce their MMR significantly. For instance, Khorog Maternity Hospital decreased its MMR from 21.3 in 2014 to 0 in 2017 partly due to the national standards [14]. This improvement in this hospital according to R9 is likely due to the adoption and implementation of the national standards: They (i.e. the national standards) 
all are evidence based and proved to be effective; we work according to WHO standards (i.e. national standards were developed based on WHO ones). I do understand, the WHO is for poor countries of course, we all know it. Regardless of this, the development of standards was useful.... Now women are given only those medicines that are prescribed in the standards. Not to put bad eyes, eclampsia is less; of course, we have them, but not too many cases. Now we only have 4 cases, in the past we had 12 and 20 . Also then women were not easily saved if they had eclampsia. Magnesium sulfate is a very good anticonvulsant medicine. It is very effective. Diazepam, magnesium sulfate, whatever fits/suits her; the woman receives her magnesium for 2 days. Then she will have a birth. In the past we examined a woman with preeclampsia and gave her metildopa and further examined her until either her baby died or she developed any other complications. Now after receiving magnesium therapy, a woman has a delivery. She either has a vaginal birth or a cesarean section depending on her health condition. These standards had a significant positive impact on maternal health. They helped a lot.

R11 stated that national standards improved management of possible lethal obstetric complications and prevented fatal outcomes. She also added that before their implementation, the international and renowned national maternity experts organized training/seminars for health providers on the procedures detailed in the national standards to improve the quality of emergency obstetric care. These training/seminars were conducted to make sure that health professionals know the procedures and are well aware of the details and specificities of the national standards. R11 states: It (i.e. maternal health) also improved because of the national standards.

There are standards how to manage hemorrhage or eclampsia. After implementation of the national standards, maternal mortality decreased and maternal health improved. We don't prescribe tons of medicines now; we prescribe only those medicines described in the standards for a certain obstetric condition. For example, standards encourage an active management of the third stage of delivery that is to inject an oxytocin and to massage a uterus every 15 minutes to prevent hemorrhage. Now after an implementation of standards, vaginal tears were decreased. In 2008, the international and national maternity experts conducted numerous trainings on national standards for obstetricians. They explained how these standards should be implemented and how they work during these trainings.

\section{Challenges of Maternal Health Care}

All interviewees agree that there are limits to the success. Despite the fact that MMR is decreasing in Tajikistan, it remains a significant public health and social issue. There are still factors that should be addressed because they continue to contribute to maternal mortality. First, an important driver of maternal mortality is the rising number of chronic health diseases (non-communicable diseases/existing conditions/extra-genital diseases) among women $(n=10)$. Health providers state that pregnant women who are referred for antenatal care to them now have more chronic health conditions such as anemia, kidney's disease, heart illnesses and hypertension in comparison with women they had seen for antenatal care in the past. According to respondents, chronic health diseases result in complications during pregnancy, delivery and postpartum period.

R6 stated: Most of our women have extra-genital illnesses (e.g. chronic health diseases) which lead to more complications during pregnancy and delivery. The majority of our maternal deaths are resulting from obstetric and gynecological complications related to chronic diseases - one died from scurvy and one from thrombocytopenic purpura. In other words, most of our obstetric complications are due to extra-genital pathologies. Many [pregnant women] have extra-genital diseases; we did not have any genital causes of maternal deaths in the past. [In the latter case] All of our doctors have sufficient work experience and could provide them with quality support.

Other respondents such as $\mathrm{R} 7$, an obstetrician with long experience of working in Tajik maternal health system, suggests that chronic health diseases are a reason for poor maternal health outcomes. Her interview also helps to understand the shift that happened in causes of maternal mortality from direct to indirect causes of obstetric deaths in Tajikistan: Most maternal deaths are due to extra-genital diseases. If in the past most women died because of hemorrhage and pre-eclampsia or eclampsia, now they die because of tuberculosis - not only our women, but women in general in Tajikistan - due to acute kidney failure and various heart diseases. Now the extra-genital pathology is the main cause.

Similarly, R1 argues that expectant mothers have more complicated health histories now when they are referred to them, however, they do not take care of their chronic health diseases before their pregnancy. R6 argues that pregnant women should have gone through medical examination well before their marriage and if chronic health diseases are diagnosed then they should have treated them. However, according to her experience, many of these women do not address their chronic health diseases before pregnancy. As a result, health care providers working in maternal health care struggle to decrease maternal mortality and improve maternal health further.

According to R1: I think that even a woman who is not pregnant should go through a medical examination because many young women have different extra-genital diseases such as anemia and problems with their kid- 
neys. Most of them have anemia, right? They need to have medical examinations and tests before pregnancy and then get pregnant. They should get tested before pregnancy and receive required treatment for anemia and kidney diseases, right? Most young women have anemia; they have 6 and 5 gr of hemoglobin and get married and get pregnant. Of course, we cannot manage to restore such a low level of hemoglobin [during pregnancy] and then they develop complications. They have hemorrhage during delivery or after birth; they develop eclampsia or pre-eclampsia, stroke and all of that. Maternal health includes all of this, right? First, they need to have tests in advance. Before marriage they need to receive treatment for anemia and kidney disease then get married. Those who have not done tests and those who do not receive treatment before pregnancy, when they become pregnant they have pre-eclampsia, eclampsia and anemia, and are not healthy. Then all pregnancies will end up having complications.

\section{Geographic Disparity}

Place of residence/geographical location plays a significant role in the maternal mortality disparity in Tajikistan according to health care providers. Despite the reduction of maternal mortality across all regions of the country, rural women still are more likely to die of complications from pregnancy and delivery than urban women.

R3 said: One particular year, we had many maternal death. Which year was that? We had many maternal deaths that year. Two women or even three died in Khokhdara. These three women died in Khokhdara itself. They were not brought here (i.e. to the maternity hospital in the town) and died there. A woman also died in the Ishkashim district.

The geographical disparity was also emphasized by other health care providers who also add that it is connected with the fact that there is lack of health care providers in the rural areas. R5 said that "a woman was delivered to us from Javshangoz, there are no any nurse in the village". R6 also states that "there are many villages that do not have nurses. It would be good to establish a medical facility there and to train a person who can work there." R6 also underpins a higher antenatal loss among rural women:

Other day, a young woman with her first pregnancy was delivered to us, she was I believe from Xic village. It was her first birth and she also had placenta abruption, these women should be provided with care on site. But we do not have a car, then there is no car, no blood in the region, no conditions in the regions (i.e. rural areas), they took her and brought her here, we opened her stomach and saw that her uterus is black. The baby died during birth intranatal, so the baby died, the uterus was removed, we were so saddened with her tragedy. The tragedy was not only because it was very difficult situation, the uterus was black and we ourselves were so sad. It was a very bad situation, we only saved the woman. In this situation, when there is a call, the emergency team with car should leave straight away. Then we could save both the baby and the uterus. R6 argues that: We had so many severe conditions, in Khorog, women come for antenatal care, doctors work well with them, if they even have a very minor issue, they call us and report that a woman has some kind of an issue. Or even doctors take her and bring her to us. There is a very good antenatal care in the Reproductive Health Center in our Khorog. In a village, when a woman has a high blood pressure she even does not go to see a midwife. In villages, there are no doctors, but nurses/ midwives. In many cases women get lazy and keep postponing their visit, they keep saying I will go tomorrow, tomorrow, then you see that they will bring her with seizure or acute insufficiency of kidneys.

Interviews with other providers not only highlight the geographical disparities in maternal mortality but also provide an insight into other layers of disparities. Many respondents $(n=12)$ agree that rural women are the poorest groups of Tajik society, they have less resources and they cannot afford expenses related to health care as well as they are less likely to have college or university degrees. In the Tajik context, where majority of people have higher education despite its overall poor quality, not having higher education means lower social and economic status and a lack of job opportunity. It is clear women who live in some rural areas are excluded from proper antenatal and obstetric care due to interplay of various factors such as rural place of residence, relative or extreme poverty, gender and lack of education. R9 states "The ones who died here are those who are not even under antenatal care or registered with doctors. Those who have poor financial situation." R2 states: The social condition, most men do not work, the income is small. Can you imagine to live on 1000 somoni? Women work a lot. If women live in villages it is even worse because they also have animals, and gardens to look after. Pregnant women are stressed out because of lack of money and financial resources/situation.

R2 states that: Some women come and complain that their husbands do not work, the women also do not work, especially those who come from villages/rural areas. If those could receive any help it would be very great. They are not provided with any services or support. Those who work certainly can find something, but the poor will not be able to.

The above interviews with health care providers help to understand the alarming multidimensional disparities between urban and rural women. However, based on existing official statistics, it is impossible to see these disparities, because official statistics do not provide any information about place of maternal death. Yet, to ad- 
dress the geographical disparity, there is a need to have correct and adequate data on rural areas' MMR and compare the causes and differences of MMR between urban and rural settings for each region to define interventions for women in rural settings.

\section{Discussion}

The study shows that Tajikistan had one of the highest MMR in the Central Asia [20]. and that tendency has been reversed in a significant way over the past decades $[13,14]$. According to health care providers' perceptions a reduction in MMR occurred due to elimination of shortcomings that served as obstacles to providing effective emergency obstetric care when complications happen. One of these barriers was lack of emergency obstetric care including ICU or laboratory in the maternity hospitals resulting in impeding providers' efforts to save women's lives and unnecessary delays. Health providers previously worked in an environment that prevented them to act fast, aggressively and effectively. This study based on providers' responses underpins an importance of improvement of emergency obstetric care and argues that all maternity hospitals should have ICU and a laboratory and birthing houses should have the most important equipment to provide basic emergency obstetric care. This study supports WHO approach to offer emergency obstetric care at all levels of health facilities as a strategy to deal with life-threatening complications during pregnancy, birth and postpartum period [21].

The present study shows that improvement of referral system among various obstetric health institutions and health providers was a critical factor in reducing MMR. The Tajik government needs to further improve this system by providing financial resources to maintain its efficacy and sustainability. Development and improvement of "referral system among health institutions at township/county/provincial levels" was emphasized in a study in China (p. 242) [22]. The present study highlights that referral system is an important aspect of maternal health organization and management and should be improved as well as must be a focus of future studies.

The current study also found that the national standards helped health providers to address the main drivers of maternal mortality and morbidity. As a result of lack of the national standards, there was inconsistent obstetric practice all over the country. The national standards describe the best medical practices to address potentially lethal obstetric complications. The national standards allowed avoiding curable complications to become fatal by providing basic procedures that do not require expensive equipment or technology. Until implementation of the national standards, there were no clear guidelines/instructions what type of obstetric health service, health providers should offer women during obstetric complications.
However, while Tajikistan implemented national standards and reduced its MMR, the USA (except California), does not implement this cost-effective strategy to control its increasing MMR. A study in Syria also recommends to develop national protocols to standardize obstetric practices during the third stage of birth and postnatal period to manage postpartum hemorrhage which is the key reason of maternal mortality in Syria [10]. The present study highlights cost effective prevention strategies that Tajikistan utilized to control its MMR which can be used in other countries and these findings can also enrich literature on maternal mortality and health.

Chronic health diseases have been identified as a serious barrier to reduction of maternal mortality and improvement of maternal health according to health care providers. They are one of the leading causes of maternal mortality in Tajikistan. Chronic health diseases increase risks of complications before, during and after childbirth as studies in other research settings reported $[1,4,5,23-29]$. The critical aspect of this study is that it highlights the obstetric transition which according to Souza, et al. a shift from direct causes to indirect causes of maternal mortality that occurs when maternal mortality decreases in countries which experienced high maternal mortality in the past $[29,30]$.

Therefore, one efficient way to improve a pregnant women's maternal health is to addressed chronic health diseases long before pregnancy and delivery [29]. Vrachnis, et al. (2011) argue that "preconceptual and early pregnancy counseling is not only essential but in some cases life-saving" (p. 18) [1]. The authors also emphasize that obstetricians have to ask advice from relevant health professionals and plan women's antenatal care and delivery method in advance [1]. Similarly, Stroke and Wilkinson (2018) suggest that health professionals must expand their scope of practice beyond pregnancy to concentrate on chronic health disease prevention before conception [29]. Whenever they diagnose chronic health diseases, they should help women to develop treatment plans for the conditions not only during pregnancy but also far beyond the postnatal period to avoid any complications in future [29]. The health care providers in this study recommend focusing on the obstetric transition, managing chronic health diseases and avoiding focusing only on direct causes of maternal mortality in Tajikistan.

Clinicians and policy makers also need to improve statistics on maternal mortality by adding the place of residence of women who died which can shed a light to the geographical disparities. They also need to improve other aspects of official statistics such as availability, reliability, and discrepancies. Lack of reliable data to better understand and comprehend the increase was found in other studies [4,3,24,3032]. Improvement of the national statistics will help to understand the extent of the problem and intro- 
duce effective measures to make motherhood safe for everyone [1]. Otherwise, as Chan argues "Without these fundamental health data, we are working in the dark. We may also be shooting in the dark" (Chan cited in Sahay, et al. 2018, p. 83) [32]. If there are no reliable data, there is no trustworthy way of knowing whether strategies are working or not [32]. It is profusely clear that the official statistics needs improvement and they should be available widely for health providers to see their progress or lack of it and to direct their interventions purposefully and efficiently.

The providers also argue that rural settings lag behind urban areas' maternal health outcomes. Geographical disparities in maternal mortality was observed in previous studies $[9,22,25,33]$.

For example, marked geographical differences in maternal mortality in a relatively small geographical setting was observed in a research in Tanzania [25].

However, the current study shows multidimensionality of the disparities, such as geographic maternal health disparities may be exaggerated by class issue/ socioeconomic condition of rural women who are usually the poorest groups of population in Tajikistan [34]. The respondents' interviews and document review help understand the multiple layers of the disparities, including misdistribution/disparities of health providers and health care facilities. The majority of health facilities are located in urban areas [35].

Urban areas also have a higher number of health professionals than rural areas [35-37]. Some remote rural areas do not have any medical facility or health professionals. The urban areas have better developed health system [38]. so it is crucial to address the misdistribution/disparities in health care providers and health facilities because "inequity in maternal mortality reflects disparities of the health care systems" (p. 750) [39]. The urban areas are also better developed in socioeconomic terms and have better transportation system and it is not surprising that urban women have higher antenatal care coverage and prefer hospital delivery. The study findings show that urban women are covered with antenatal and obstetric care relatively well while rural women are overlooked and the health systems clearly fail rural women who experience higher maternal deaths.

To address the multidimensional disparities in maternal mortality it is important to improve the quality of existing health facilities and to establish health facilities in rural settings that do not have one; to enhance economic development and transportation system of rural settings. The Tajikistan's government envisages to develop rural settings according to the National Strategy Plan for 2030, [40]. but more focus should be on health sector and rural health disparities. Improvement of health care is not sufficient because midwives cannot reach pregnant women with complications and provide antenatal care due to lack of transports [41].
If roads of the village are not improved and affordable transportation does not exist it is only possible to reduce maternal mortality to a certain level [41]. In addition, a national priority should be training of midwives who will work in rural settings, but there is a challenge to recruit them after training in cities to work in rural health facilities [41]. Even when midwives were recruited with agreement to come back to villages to provide health care, some midwives still did not return [41]. However, improvement of ratios of health providers contribute to improvement of health care, [42]. therefore, the Tajik government should address the misdistribution/disparities of health providers by using other incentives.

Governments in Afghanistan and Ethiopia use intersectoral or multisectoral cooperation to decrease maternal mortality which also reflects the purpose of the Sustainable Development Goals (SDGs) to work across the sectors $[6,41]$.

Maternal mortality is a multifactor phenomenon and the Tajik government also needs to collaborate with other sectors, for example the Ministries of Transportation, Education, Finance, Labor, other international health organizations and non-government organizations to address the issue. Intersectoral approach is certainly a way to go in Tajikistan as well.

The maternal mortality is certainly not a neglected issue in Tajikistan. The study findings illustrate positive effects of recent government policies and programs but it also shows how they neglects the shift that happens in causes of maternal mortality and geographic disparities or more correctly the multidimensional disparities in maternal mortality in Tajikistan. No state programs or documents discuss the multidimensional inequities in maternal mortality in the rural areas and how to address it. It will not be possible to further successfully reduce the persistent high maternal mortality among poor and marginalized rural women, unless the multidimensional disparities are addressed. The study findings should be taken into account while developing and implementing programs and policies to improve the quality of obstetric care and to design maternal health system. They also should guide the government's policies and strategies, international health organizations' programs and actions of health professionals to further decrease maternal mortality. However, other stakeholders involved in maternal care also should address the multifactoral disparities while implementing intervention programs.

\section{Disclosure}

This research was supported in part by a grant from the College of Social and Behavioral Sciences' research support program Northern Arizona University. 


\section{References}

1. Vrachnis N, lliodromiti S, Samoli E, lliodromiti Z, Dendrinos S, et al. (2011) Maternal mortality in greece, 1996-2006. Int J Gynecol Obstet 115: 16-19.

2. Esienumoh EE, Allotey J, Waterman H (2018) Empowering members of a rural southern community in nigeria to plan to take action to prevent maternal mortality: A participatory action research project. J Clin Nurs 27: e1600-e1611.

3. MacDorman MF, Declercq E (2018) The failure of the united states maternal mortality reporting and its impact on women's lives. Birth 45: 105-108.

4. MacDorman MF, Declercq E, Thoma ME (2018) Trends in texas maternal mortality by maternal age, race/ethnicity, and cause of death, 2006-2015. Birth 45: 169-177.

5. Nyflot L, Sitras V (2018) Strategies to reduce global maternal mortality. Acta Obstet Gynecol Scand 97: 639-640.

6. Tessema GA, Laurence CO, Melaku YA, Misganaw A, Woldie SA, et al. (2017) Trends and causes of maternal mortality in ethiopia during 1990-2013: Findings from the global burden of diseases study 2013. BMC Public Health 17: 160.

7. Donati S, Maraschini A, Lega I, D'Aloja P, Buoncristiano M, et al. (2018) Maternal mortality in italy: Results and perspectives of record-linkage analysis. Acta Obstet Gynecol Scand 97: 1317-1324.

8. Donati S, Senatore S, Ronconi A (2018) Maternal mortality in italy: A record linkage study. BJOG 118: 872-879.

9. De Graaf JP, Schutte JM, Poeran JJ, van Roosmalen J, Bonsel GJ, et al. (2012) Regional difference in dutch maternal mortality. BJOG 119: 582-588.

10. Almerie MQ, Matar HE, Almerie Y (2011) A 20-year (19892008) audit of maternal mortality in damascus, Syria. Int J Gynaecol Obstet 112: 70-71.

11. Ronsmans C, Graham WJ (2006) Maternal mortality: Who, when, where, and why. Lancet 368: 1189-1200.

12. Baranov AA (1991) Maternal and child health problems in the USSR. Arch Dis Child 66: 542-545.

13. World Health Organization (WHO) (2014) Trends in maternal mortality 1990-2013.

14. (2018) Republican Medical Statistical Center (RMSC) under the Ministry of Health and Social Protection of the Republic of Tajikistan. Maternal mortality, 2008-2017. Dushanbe: RMSC.

15. Falkingham J (2004) Poverty, out-of-pocket payments and access to health care: Evidence from tajikistan. Soc Sci Med 58: 247-258.

16. Habibov NN, Fan L (2008) Modelling prenatal health care utilization in tajikistan using a two-stage approach: Implications for policy and research. Health Policy Plan 23: 443451.

17. Walker G (2008) A review of the population and reproductive health situation in the Republic of Tajikistan. Dushanbe: UNFPA.

18. QSR International (2009) NVivo 12 Plus for Windows.

19. Nancy A Naples, Carolyn Sachs (2000) Standpoint epistemology and the uses of self-reflection in feminist ethnography: Lessons for rural sociology. Rural Sociology 65: 194214.

20. Mashta $O$ (2000) Dushanbe: Building capacity for primary care in Tajikistan. The Lancet 355: 295.

21. World Health Organization (2009) Monitoring emergency obstetric care: A handbook 2009.

22. Liang J, Dai L, Zhu J, Li X, Zeng W, et al. (2011) Preventable maternal mortality: Geographic/rural-urban differences and associated factors from the population-based maternal mortality surveillance system in China. BMC Public Health 11: 243

23. Hirshberg A, Srinivas SK (2017) Epidemiology of maternal morbidity and mortality. Semin Perinatol 41: 332-337.

24. Lawson GW, Keirse MJ (2013) Reflections on the maternal mortality millennium goal. Birth 40: 96-102.

25. Manyeh AK, Nathan R, Nelson G (2018) Maternal mortality in Ifakara health and demographic surveillance system: Spatial patterns, trends and risk factors, 2006-2010. PLoS One 13: e0205370.

26. McCall SJ, Nair M, Knight M (2016) Factors associated with maternal mortality at advanced maternal age: A population-based case-control study. BJOG 124: 1225-1233.

27. Mhyre JM (2012) Maternal mortality. Curr Opin Anaesthesiol 25: 277-285.

28. Nelson DB, Moniz MH, Davis MM (2018) Population-level factors associated with maternal mortality in the United States, 1997-2012. BMC Public Health 18: 1007.

29. Strokes MJ, Wilkinson JP (2018) The causes of maternal mortality are changing and preventable. BJOG 125: 1262.

30. Reid A, Garrett E (2018) Medical provision and urban-rural differences in maternal mortality in late nineteenth century Scotland. Soc Sci Med 201: 35-43.

31. Population Council (2011) Trends in maternal mortality, 1990-2008. Popul Dev Rev 37: 211-214.

32. Sahay S, Nielsen P, Latifov M (2018) Grand changes of public health: How can health information systems support facing them. Health Policy Technol 7: 81-87.

33. Smith BL, Sandlin AT, Bird TM, Steelman SC, Magann EF (2014) Maternal mortality in the mississippi delta region. South Med J 107: 275-279.

34. National Coordination Committee to Prevent and Control HIVIAIDS, Tuberculosis and Malaria in Republic of Tajikistan (2008) Social and hygienic aspects of labor migration of population of the Republic of Tajikistan.

35. Mirzoev T, Green A, Newell J (2010) Health SWAps and external aid - a case study from Tajikistan. Int $\mathrm{J}$ Health Plann Manage 25: 270-286.

36. Fan L, Habibov NN (2009) Determinants of accessibility and affordability of health care in post-socialist Tajikistan: Evidence and policy options. Glob Public Health 4: 561574.

37. Parfitt BA, Cornish F (2007) Implementing family health nursing in Tajikistan: From policy to practice in primary health care reform. Soc Sci Med 65: 1720-1729.

38. Habibov N (2010) Hospitalization in Tajikistan: Determinants of admission, length of stay, and out-of-pocket expenditures. Results of a national survey. Int J Health Plann Manage 25: 251-269.

39. Ren Y, Qian P, Duan Z, Zhao Z, Pan J, et al. (2017) Disparities in health system input between minority and non-minority counties and their effects on maternal mortality in Sichuan province of western China. BMC Public Health 17: 750.

40. (2016) National development strategy of the republic of Tajikistan for the period up to 2030.

41. Britten S (2017) Maternal mortality in Afghanistan: Setting achievable targets. Lancet 389: 1960-1962.

42. Srofenyoh EK, Kassebaum NJ, Goodman DM, Olufolabi AJ, Owen MD (2016) Measuring the impact of a quality improvement collaboration to decrease maternal mortality in a Ghanaian regional hospital. Int J Gynaecol Obstet 134: 181-185. 